\title{
Episodic Ataxia Type 2
}

\author{
Michael Strupp, Andreas Zwergal, and Thomas Brandt
}

Department of Neurology, University of Munich, Munich, Germany

\begin{abstract}
Summary: Episodic ataxia type 2 (EA 2) is a rare neurological disorder of autosomal dominant inheritance resulting from dysfunction of a voltage-gated calcium channel. It manifests with recurrent disabling attacks of imbalance, vertigo, and ataxia, and can be provoked by physical exertion or emotional stress. In the spell-free interval, patients present with central ocular motor dysfunction, mainly downbeat nystagmus. A slow progression of cerebellar signs accompanied by a slight atrophy of midline cerebellar structures is commonly observed during the course of the disease. EA 2 is caused most often by the loss of function mutations of the calcium channel gene CACNA1A, which encodes the $\mathrm{Ca}_{\mathrm{v}} 2.1$ subunit of the P/Q-type calcium channel and is primarily expressed in Purkinje cells. To date, more than 30 mutations have been described. Two effective treatment options have been established for EA 2: acetazol-
\end{abstract}

amide (ACTZ), which probably changes the intracellular $\mathrm{pH}$ and thereby the transmembraneous potential, and 4-aminopyridine (4-AP), a potassium channel blocker. Approximately $70 \%$ of all patients respond to treatment with ACTZ, but the effect is often only transient. In an open trial, 4-AP prevented attacks in five of six patients with EA 2, most likely by increasing the resting activity and excitability of the Purkinje cells. These findings were confirmed by experiments in animal models of EA 2. Many aspects of the pathophysiology (e.g., induction of the attacks) and treatment of EA 2 (e.g., mode of action of ACTZ and 4-AP) still remain unclear and need to be addressed in further animal and clinical studies. Key Words: Episodic ataxia type 2, downbeat nystagmus, PQ-calcium channel, acetazolamide, aminopyridine.

\section{INTRODUCTION}

The first purpose of this review on episodic ataxia type 2 (EA 2) is to describe its clinical features, genetics, and the correlation between mutations and clinical findings, as well as the current treatment options. Special emphasis is placed on the pharmacological effects of the two agents currently used for treatment: acetazolamide (ACTZ) and 4-aminopyridine (4-AP). The second purpose is to address open questions in EA 2, namely the pathophysiology of the induction of the attacks, the mechanisms of action of ACTZ and 4-AP, and the absence of randomized, controlled trials.

The current classification of different types of episodic ataxia (EA) is based on genetics and clinical presentation. To date, there are six genetically defined types of EA, all of them autosomal dominant. Some other diseases that characteristically have the same clinical presentation as EA have not yet been genotyped. Given the variety of their clinical presentations, it seems logical to

Address correspondence and reprint requests to: Michael Strupp, M.D., Department of Neurology, University of Munich, Marchioninistrasse 15, 81377 Munich, Germany. E-mail: Michael.Strupp@med. uni-muenchen.de. classify the EAs on a predominantly genetic basis. More detailed information about the coherence of genotype and phenotype will lead to modifications and expansion in the future.

Episodic ataxia type 1 (EA 1) is characterized by brief attacks of ataxia, lasting for minutes, that are provoked by abrupt postural changes, emotional stress, and vestibular stimulation. Between spells, the patients have neuromyotonia: that is, an ongoing spontaneous highfrequency muscle fiber activity due to axonal hyperactivity. ${ }^{1}$ EA 1 is caused by missense point mutations of the voltage-gated potassium channel KCNA1 protein (chromosome band 12p13), which forms the Kv1.1 channels and is expressed in the peripheral and central nervous systems (OMIM \#160120). These mutations lead to an altered neuronal excitability by affecting the temporal integration and action potential firing rates. ${ }^{2}$ First-choice treatment options are phenytoin and carbamazepine. ${ }^{3}$ (For details, see the article by Kordasiewicz and Hanna. ${ }^{67}$ )

Patients with EA 2, the focus of this review, present with attacks of imbalance, vertigo, and ataxia. EA 2 is the most frequent subtype of episodic ataxia.

EA 3, a very rare disorder, has so far been described in 
only one family (chromosome 1q 24, OMIM \%606554). It is characterized by recurrent attacks (lasting minutes to hours) with vestibular ataxia, vertigo, tinnitus, and headache and (in half of the patients) with interictal myokymia. ${ }^{4}$ Patients respond to ACTZ.

In EA 4, patients have recurrent episodes of vertigo, ataxia, and diplopia, slowly progressive ataxia, and impaired smooth-pursuit eye movements. ${ }^{5}$ These patients do not have myokymia and do not respond to ACTZ. No genetic locus has been identified (OMIM \%606552).

EA 5 is caused by mutations of the calcium channel CACNB4 $\beta 4$ protein (chromosome region $2 \mathrm{q} 22 \sim \mathrm{q} 23$; OMIM +601949), which lead to attacks of vertigo, ataxia, and seizures. One mutation causes juvenile myoclonic epilepsy. ${ }^{6}$ The onset of symptoms is in the third and fourth decades. The attacks last hours (sometimes weeks); between the attacks patients have downbeat nystagmus, postural imbalance, and ataxia. Symptoms respond to ACTZ.

Another form with recurrent attacks of ataxia with seizures, migraine, and alternating hemiplegia has been reported more recently in one patient; it was classified as EA 6. Symptoms began in early childhood, due to a missense mutation in the SLClA3 gene encoding a glutamate transporter EAAT1 protein on chromosome band $5 \mathrm{p} 13$. The mutations lead to a reduced capacity of the glial glutamate transporter and less glutamate uptake, which may result in neural hyperexcitability and cause seizures and alternating hemiplegia. ${ }^{7}$

It must be emphasized that other diseases characterized by the clinical presentation of episodic ataxia exist that have not yet been formally classified as EA. For example, episodic ataxia lasting approximately $20 \mathrm{~min}$ - utes but with large variability in attack frequency associated with paroxysmal choreoathetosis, paresthesias and spasticity, has been described with a locus on chromosome 1p. Attacks are precipitated by emotional and physical stress as well as by alcohol and fatigue. ${ }^{8}$ Patients respond to ACTZ.

\section{CLINICAL FEATURES OF EPISODIC ATAXIA TYPE 2}

Episodic ataxia type 2 (EA 2) usually begins in early childhood, most often before the age of 20. Rarely, however, symptoms may first manifest in patients older than 50 years. ${ }^{7,9-11}$ Such late onset may be related to certain mutations, such as, for example, multiple-base pair insertions in CACNA1A. ${ }^{12}$ Clinically, EA 2 is characterized by recurrent attacks of ataxia lasting for several hours to days, which are provoked by physical exertion, emotional stress, or alcohol. ${ }^{9,13}$ Several patients also have mild myasthenic symptoms (due to impaired neuromuscular transmission; see below). Attacks may occur daily or over longer intervals, even years in some patients. The most recent large case series from Jen et al. ${ }^{14}$ described the clinical spectrum in 18 families and nine sporadic cases; 64 patients were genetically defined. All but 2 of these 64 patients reported episodes of ataxia; two members of one family had only progressive ataxia. All but one had experienced onset before age 20. Migraine headaches occurred in more than half. ${ }^{14}$ These findings indicate that the clinical patterns of EA 2 and vestibular migraine are related (Table 1). Both disorders are characterized by a combination of episodic vertigo or ataxia as well as ocular motor disturbances in the spell-free

TABLE 1. Differentiation of Episodic Ataxia Type 2 and Vestibular Migraine

\begin{tabular}{|c|c|c|}
\hline & Picture of EA 2 & Picture of VM \\
\hline Clinical features & $\begin{array}{l}\text { - Recurrent attacks of vertigo, imbalance and } \\
\text { ataxia (minutes to hours) } \\
\text { - Migraine headaches }(>50 \%) \\
\text { - Familial history in the majority }\end{array}$ & $\begin{array}{l}\text { - Spontaneous recurrent attacks of } \\
\text { vertigo/dizziness (minutes to hours) } \\
\text { - Associated headache or other } \\
\text { migrainous symptoms ( } 60 \%-70 \%) \\
\text { - Individual or familial history of } \\
\text { migraine in the majority }\end{array}$ \\
\hline $\begin{array}{l}\text { Examination findings } \\
\text { during attacks }\end{array}$ & $\begin{array}{l}\text { - Pathological positional nystagmus }(70 \%) \\
\text { - Ataxia/postural imbalance }(>90 \%)\end{array}$ & $\begin{array}{l}\text { - Pathological spontaneous or positional } \\
\text { nystagmus }(70 \%) \\
\text { - Postural imbalance }(90 \%)\end{array}$ \\
\hline During attack-free interval & - Central ocular motor signs $(>90 \%)$ & $\begin{array}{l}\text { - Central ocular motor signs }(>60 \%) \\
\text { - Peripheral vestibular deficit }(10 \%-20 \%)\end{array}$ \\
\hline Genetic background & - $C A C N A 1 A$ mutations (60\%) & $\begin{array}{l}\text { - } C A C N A 1 A \text { mutations in FHM } \\
\text { - None found to date in VM }\end{array}$ \\
\hline Treatment of choice & - Acetazolamide, 4-aminopyridine & - Beta-blockers, valproate \\
\hline
\end{tabular}

EA 2 and VM cannot be differentiated solely by clinical presentation. Both disorders are characterized by a combination of episodic vertigo or ataxia as well as ocular motor disturbances in the spell-free interval. Monosymptomatic presentations of VM without headaches occur in up to $30 \%$ of patients. In a subgroup of patients with FHM, there is a genetic linkage to the CACNA1A gene, which is the locus most often mutated in EA 2. The frequency of CACNA1A gene mutations in ordinary vestibular migraine is not known. Data adapted from Jen et al., $2004,{ }^{14}$ and Brandt and Strupp, 2006. ${ }^{15}$

EA 2 = episodic ataxia type $2 ; \mathrm{FHM}=$ familial hemiplegic migraine; $\mathrm{VM}=$ vestibular migraine. 
interval (see below). It should be noted that headaches do not occur in up to $30 \%$ of patients with vestibular migraine. $^{15-17}$

Between spells, more than $90 \%$ of patients exhibit central ocular motor disturbances such as gaze-holding deficits, saccadic smooth pursuit, impaired visual suppression of the vestibulo-ocular reflex, especially downbeat nystagmus, ${ }^{18}$ or rarely bilateral internuclear ophthalmoplegia. ${ }^{19}$ Some of these patients develop subtle and slowly progressive limb ataxia and postural imbalance later in life. Mental retardation has also been reported. ${ }^{20}$ Several patients have complained of generalized (myasthenic) weakness; patients rarely suffer from dystonia, which may be a late feature of the disease. ${ }^{21}$ Others have hemiplegic episodes or absence seizures. EEG abnormalities were reported in patients with acetazolamide-responsive ataxia. ${ }^{22}$ Imbrici et al. ${ }^{23}$ described a family in which absence seizures segregate in an autosomal dominant fashion through three generations. Five members exhibited a combination of absence epilepsy (with 3-Hz spike-waves) and cerebellar ataxia.

Cerebellar atrophy, especially of the anterior vermis, can be detected on MRI. ${ }^{24,25}$ Decreased high-energy phosphate ratios, reduced total creatine, increased $\mathrm{pH}$ (most likely due to an intracellular alkalosis), and high lactate peaks have also been found in the cerebellum of patients with EA $2 .^{26,27}$

\section{GENETICS AND PATHOPHYSIOLOGY}

The autosomal dominant hereditary disorder EA 2 is commonly (see below) caused by mutations of the calcium channel gene CACNAIA on chromosome 19p13. ${ }^{10,28,29}$ This gene encodes the $\mathrm{Ca}_{\mathrm{v}} 2.1$ subunit of the P/Q-type calcium channel (2261 amino acids), which acts as the voltage sensor and ion-conducting pore. ${ }^{30}$ More than 30 mutations distributed throughout the gene have been described. Most of them are nonsense or frameshift mutations that lead to a disruption of the reading frame, or intronic mutations that predict aberrant splicing. ${ }^{10,31,32}$ There have also been reports of missense mutations (T4747C transition in the highly conserved transmembrane segment S6; AY1593/1594D), which result in a loss of function of the expressed CACNAIA protein. $^{33,34}$ At least two families with CAG-repeat expansions of the CACNA1A gene (defining the SCA 6 genotype) have been reported whose clinical presentation was indistinguishable from EA $2 .^{35}$

EA2 is allelic with familial hemiplegic migraine type 1 , which is almost exclusively caused by gain-offunction mutations, resulting in an increase of calcium flow through the CACNA1A channel. ${ }^{36}$ The spinocerebellar ataxia type 6 is also caused by a genetic alteration of the CACNAIA gene, with small, characteristic expan- sions of a CAG repeat within the last exon of this gene. ${ }^{37}$ (For further details, see article by Rajakulendran et al. ${ }^{68}$ )

Despite the loss-of-function mutations in EA 2, one intact gene still expresses the normal ion-channel protein due to heterozygosity; however, the channel density and the calcium currents are reduced, ${ }^{34}$ and thus neurotransmitters are released (namely, GABA in Purkinje cells and acetylcholine at the neuromuscular junction). ${ }^{38,39}$ For this reason, it is assumed that ataxia is caused by impaired neurotransmission. It was also shown that the misfolded mutant CACNA1A protein impairs plasma membrane trafficking and targeting of the functioning CACNA1A proteins in a pronounced and basically negative way in both nonsense and missense CACNAIA mutations. ${ }^{32}$ These mutations were associated with a more pronounced and progressive ataxia between the attacks.

Some mutations are associated with certain additional clinical features, such as absence epilepsy. ${ }^{12,40}$ Ataxic spells induced by fever or high environmental temperature were associated with a certain CACNA1A mutation (nucleotides $1253+1 \mathrm{G} \rightarrow \mathrm{A}$ ). Overall, however, there is no simple genotype-phenotype correlation as different types of mutations (missense vs. nonsense) at distinct loci within the CACNA1A gene lead to similar symptoms. $^{14}$

Notably, no mutation of the CACNA1A gene can be detected in approximately $30 \%$ to $50 \%$ of all patients presenting with typical clinical features of EA 2. ${ }^{14,31,41}$ In some of these patients, other EA 2 genes have been postulated: for example, on chromosome band $1 \mathrm{q} 42$ (peak 2-point lod score of 4.14). ${ }^{42} \mathrm{~A}$ mutation in the "Ca $2.1 \alpha$ subunit" leads to cerebellar ataxia and absence epilepsy. Its coexpression with CACNA1A resulted in an impairment of the channel function $\mathrm{Ca}_{\mathrm{v}} 2 .{ }^{23}$ Further, a novel mutation of the KCNAl gene causes EA without myokymia, highlighting the heterogeneity of phenotypic effects. $^{43}$

The P/Q-channel (the $\mathrm{P}$ stands for Purkinje, $\mathrm{Q}$ for granular cells) is expressed mainly in the cerebellum and (presynaptically) at the neuromuscular junction. ${ }^{30}$ This anatomical pattern of expression of the P/Q-channel may explain the ataxia, cerebellar atrophy, and the (mild) myasthenic symptoms. These latter symptoms correlate with electrophysiological findings, which revealed a reduction of the endplate potential and quantal release of acetylcholine at the neuromuscular endplate, leading to a presynaptic failure. Single-fiber electromyography showed that jitter was blocked, which improved with increased stimulation frequency. ${ }^{38}$

Mutations lead to changes not only in ion currents and the release of neurotransmitters, but also in $\mathrm{pH}$ and metabolism, which may be related to the induction of the attacks and neurodegeneration. Localized phosphorus $\left({ }^{31} \mathrm{P}\right)$ and proton $\left({ }^{1} \mathrm{H}\right)$ magnetic resonance spectroscopy 
were performed in the cerebellum and the occipital lobe of six patients with EA 2. The ${ }^{31} \mathrm{P}$ magnetic resonance spectroscopy showed decreased high-energy phosphate ratios in the cerebrum and increased $\mathrm{pH}$ in the cerebellum and cerebrum in untreated patients. The ${ }^{1} \mathrm{H}$ magnetic resonance spectroscopy revealed high lactate peaks in three of the six patients. These metabolic alterations were probably induced by the calcium channelopathy and may characterize EA $2 .{ }^{44}$

Such abnormalities on cerebellar MRI spectroscopy have been interpreted to indicate intracellular alkalosis. ${ }^{26,44}$ Harno et al. ${ }^{27}$ used proton MR spectroscopy to examine cerebellar and thalamic metabolism of nine mostly nonataxic EA 2 family members (all with proven CACNA1A mutation) and nine healthy control subjects. Cerebellar total creatine was lower in the patient group $(P=0.005)$ than in control subjects, possibly reflecting an early sign of calcium channel dysfunction in EA $2 .{ }^{27}$

It is still unclear how the mutations and additional changes are related to the precipitation of attacks by physical and emotional stress or alcohol. Changes in $\mathrm{pH}$ or transmitters are assumed to underlie the attacks, but this is still an open question, one that can best be evaluated in animal models of EA 2.

\section{ANIMAL MODELS OF EPISODIC ATAXIA TYPE 2}

There are several animal models of mutations in the CACNAIA gene (e.g., the tottering mouse, leaner mouse, rolling mouse Nagoya). ${ }^{45}$ The tottering mouse mutant contains a homozygous spontaneous C-to-T change at position 1802, which leads to a nonconservative prolineto-leucine amino acid substitution near the conserved $\mathrm{P}$ domain of the CACNAIA protein. ${ }^{45}$ This mutation alters the pore function of the $\mathrm{P} / \mathrm{Q}$ calcium channel and thereby reduces calcium currents, particularly in cerebellar Purkinje cells, where these channels are most abundant. ${ }^{39}$ Like patients with EA 2, the tottering mouse suffers from episodic attacks of ataxia induced by emotional and chemical stress. This animal model is most suitable for systematically analyzing the mechanism underlying attack precipitation (e.g., withdrawal or caffeine) and the principles of treatment. To date, it has been demonstrated that attacks are prevented by noradrenergic blockade; however, agents that facilitate noradrenergic neurotransmission failed to induce attacks. ${ }^{46}$ Thus, we must assume that alterations of noradrenergic neurotransmission contribute to attack initiation but in themselves alone are insufficient to induce attacks. ${ }^{46}$ Another study showed that aminopyridines (4-AP; 3,4-DAP) effectively prevent attacks in tottering mice. ${ }^{47}$

The leaner mouse mutant also harbors a homozygous spontaneous mutation in the gene encoding the voltageactivated $\mathrm{Ca}^{2+}$ channel $\alpha 1 \mathrm{~A}$ subunit, the pore-forming subunit of P/Q-type $\mathrm{Ca}^{2+}$ channels. ${ }^{48}$ On the basis of this mutation, an out-of-frame splicing event in the carboxy terminus occurs which results in dramatic reductions in P-type $\mathrm{Ca}^{2+}$ channel function in cerebellar Purkinje neurons. These mice show degeneration of differentiated granule, Golgi, and Purkinje cells within the cerebellum. Leaner mice show features similar to those of tottering mice but have more severe ataxia. ${ }^{45}$

Another mutation of the $\alpha 1 \mathrm{~A}$ gene has been identified in the rolling Nagoya mouse mutant. It leads to a chargeneutralizing arginine-to-glycine substitution at position 1262 in the voltage sensor-forming segment S4 in repeat III. ${ }^{49}$ These mice represent an intermediate phenotype, one that develops a more severe ataxia than the tottering mouse but lacks motor seizures.

Although most studies in mice have focused on synaptic transmission, some recent studies show that the precision of Purkinje cell pacemaking is lost in all the mutant mouse models. This loss causes degradation of synaptic information. ${ }^{39}$ The restoration of the aberrant pacemaking also alleviated symptoms, thus providing a new target for treatment. ${ }^{47}$

\section{TREATMENT OPTIONS AND PRINCIPLES}

Based on the pathophysiological understanding of EA 2, two established pharmacologic approaches focus on modulating the $\mathrm{pH}$ level and membrane ion conductance: ACTZ and 4-AP.

\section{Acetazolamide}

Currently, ACTZ is the drug of first choice for preventive treatment of EA, with dosages of 250 to $1000 \mathrm{mg}$ per day, although its efficacy has never been proven in a randomized controlled trial. ${ }^{50-52}$ ACTZ is a carbonic anhydrase inhibitor, which was initially shown to decrease the number of attacks in hypokalemic periodic paralysis patients. ${ }^{53-56}$ Its efficacy, discovered accidentally in a patient with EA 2 misdiagnosed as having periodic paralysis, ${ }^{51}$ was later confirmed by others. ${ }^{57,58}$ ACTZ effectively prevents or attenuates the attacks in approximately $50 \%$ to $75 \%$ of all patients. Clinical experience, however, shows that many patients stop treatment with this agent in the long run, because it is either no longer effective or they develop adverse effects (unpublished observation).

ACTZ has several effects. It inhibits the carbonic anhydrase interconversion of $\mathrm{CO}_{2}+\mathrm{H}_{2} \mathrm{O} \leftrightarrow \mathrm{H}_{2} \mathrm{CO}_{3}$. It causes diuresis, initial kaliuresis, and metabolic acidosis. ACTZ also lowers serum bicarbonate levels and reduces the amount of brain lactate and pyruvate, resulting in subsequent brain acidosis. ${ }^{58}$ The mechanism by which ACTZ prevents attacks-most likely via changes in $\mathrm{pH}$ - may be a key to understanding the disease pathomechanism, especially how the attacks are triggered. 
Changes in extracellular and intracellular $\mathrm{pH}$ cause alterations of the transmembrane conductance: for instance, a decrease in intracellular $\mathrm{pH}$ reduces potassium conductance, an increase in $\mathrm{pH}$ raises it. ${ }^{30}$ As we have noted, magnetic resonance spectroscopy showed that abnormal intracellular $\mathrm{pH}$ levels in the cerebellum of untreated patients with EA 2 normalized with ACTZ treatment. ${ }^{26,44}$ Thus, one hypothesis is that attacks are secondary to abnormally high intracellular $\mathrm{pH}$ values and that it is by reducing this $\mathrm{pH}$ level that ACTZ may prevent attacks. ${ }^{11}$ Lower $\mathrm{pH}$ values reduce potassium conductance of the cell membrane and have an effect on the activation and inactivation of sodium and calcium channels, respectively. ${ }^{30}$ Thus, the excitability and resting activity of neurons are restored. Without ACTZ, attacks may be precipitated by exercise and stress (hyperventilation), raising intracellular $\mathrm{pH}$ further.

As already noted, ACTZ is also effective for treating hypokalemic periodic paralysis, which is caused by mutations of a sodium channel gene $(S C N 4 A) .{ }^{55}$ Here, the mechanism might also involve regulation of potassium ion and proton concentrations. To determine whether a change of the proton concentration influences the gating of SCN4A mutants, Kuzmenkin et al. ${ }^{59}$ used $\mathrm{pH}$ values ranging from 6.4 to 8.4 in bath or pipette solutions. The change of extracellular $\mathrm{pH}$ had profound effects on steady-state activation and inactivation of the wild-type channels, probably due to the change in surface potential but also to a direct blockade of the sodium channels. ${ }^{60}$ The effect of intracellular $\mathrm{pH}$ on wild-type sodium channels was rather small. This suggests that ACTZ-induced metabolic acidosis probably has a therapeutic effect only by changing the steady-state properties of the mutants, and not their level of expression. Finally, Spacey et al. ${ }^{61}$ also demonstrated that ACTZ does not have a direct effect on either the wild-type or the mutated P/Q-channel. Thus, its mechanism of action most likely involves changes of $\mathrm{pH}$ that alter the transmembrane potential and excitability of neurons. ${ }^{61}$

Possible adverse effects of ACTZ include nephrolithiasis, hyperhydrosis, paresthesia, muscle stiffness with easy fatigability, and gastrointestinal disturbances. Side effects are dose-related and can be partially reduced by potassium chloride supplementation. Sulthiame, another carbonic anhydrase-inhibiting drug, has also been used successfully. It caused fewer side effects and was most effective in dosages between 50 and $300 \mathrm{mg}$ daily. ${ }^{62}$ Nevertheless, ACTZ is the drug of first choice, with sulthiame as an alternative treatment option. Recently, Scoggan et al. ${ }^{63}$ identified a new missense mutation in exon 12 of the CACNAIA gene from a patient with EA 2; the symptoms were controlled with a combination of ACTZ and valproic acid.

There are only a few reports on the effect of ACTZ on interictal nystagmus and progressive cerebellar degener- ation. The original ACTZ-responsive family has not shown any progression of ataxia for more than 20 years. ${ }^{9}$ Others have reported an improvement of interictal cerebellar signs. ${ }^{13}$ More recently ACTZ was demonstrated to improve neuro-otological abnormalities such as saccadic hypermetria and gaze-evoked nystagmus in a family with EA 2. These observations need to be investigated in a long-term randomized controlled trial.

\section{4-Aminopyridine}

It was recently shown that aminopyridines (such as potassium channel blockers) improve downbeat nystagmus, ${ }^{64}$ most likely by increasing the inhibitory influence of the Purkinje cells, a hypothesis that findings in animal experiments have supported. ${ }^{65}$ Because Purkinje cell function is assumed to be impaired in EA 2 and downbeat nystagmus, the effects of 4-AP on the occurrence of attacks were evaluated in three patients with EA 2. Attacks of ataxia were completely prevented in two patients with EA 2 (who no longer responded to ACTZ) and markedly reduced in a third by the potassium channel blocker 4-AP. All patients fulfilled the recently published diagnostic criteria for EA $2^{14}$; the diagnosis was confirmed in two patients in whom mutations in the CACNA1A gene were detected. Cessation of the treatment led to a recurrence within 1 to 2 days. Subsequent therapy with 4-AP alleviated the symptoms. In the meantime, four patients with genetically proven EA 2 and two patients with the clinical picture of EA 2 have been treated with 4-AP; five of the six had a full response.

The question arises as to how to explain the effects of 4-AP. As already noted, the loss-of-function mutations lead to the reduction of calcium-dependent neurotransmitter release, especially of the Purkinje cells. ${ }^{66}$ It is, therefore, assumed that ataxia in EA 2 is due to a dysfunction of the Purkinje cells, which leads to a reduced release of the inhibitory transmitter GABA. Thus, 4-AP may prevent attacks in EA 2 and improve downbeat nystagmus by increasing the release of GABA in the Purkinje cells. The following mechanisms also appear to be involved: 1) Animal experiments have shown that 4-AP increases the excitability of Purkinje cells; 1 to 10 micromolar concentrations of 4-AP markedly shortened the latency of calcium spike firing after the onset of depolarizing pulses. ${ }^{65}$ 2) 4-AP prolongs the duration of action potentials and increases the release of neurotransmitters by blocking several potassium currents: for example, the A-current and the delayed-rectifier current. ${ }^{30}$

These effects of 4-AP were further evaluated in animal models of EA 2. It is remarkable that 4-AP was observed to completely prevent attacks of ataxia in the tottering mouse, but it did not affect the severity of breakthrough attacks that occurred in the presence of a drug. These results suggest that the aminopyridines increase the threshold for attack initiation without mitigating the 
character of the attack. ${ }^{47}$ From a clinical point of view, a prospective randomized controlled study is necessary to prove the short- and long-term effects of 4-AP and to compare them with ACTZ, which remains the standard treatment for EA 2.

\section{Future treatment trials}

First of all, it will be necessary to improve our knowledge of the pathophysiology of EA 2, especially of the mechanisms underlying attack provocation. As a second step, the mechanisms of action of ACTZ and 4-AP should be investigated more thoroughly. Both issues are best addressed by electrophysiological and genetic examination in the animal models.

The therapeutic effects of ACTZ and 4-AP should be evaluated and compared in randomized controlled treatment trials. The focus should be on the short-term effects (e.g., attack prevention and improvement of interattack central ocular motor dysfunction), as well as on the longterm effects on progressive cerebellar signs and symptoms. It will also be necessary to correlate different genotypes to the pharmacologic responses.

Finally, these studies should include approaches to clearly differentiate EA 2 from vestibular migraine on a genetic basis, because the clinical manifestations of both may be indistinguishable in many patients (Table 1).

Acknowledgments: We thank Judy Benson for copyediting this manuscript.

\section{REFERENCES}

1. Browne DL, Gancher ST, Nutt JG, et al. Episodic ataxia/ myokymia syndrome is associated with point mutations in the human potassium channel gene, KCNA1. Nat Genet 1994;8:136140.

2. Maylie B, Bissonnette E, Virk M, Adelman JP, Maylie JG. Episodic ataxia type 1 mutations in the human Kv1.1 potassium channel alter $h K v \beta 1$-induced N-type inactivation. J Neurosci 2002;22: $4786-4793$.

3. Vaamonde J, Artieda J, Obeso JA. Hereditary paroxysmal ataxia with neuromyotonia. Mov Disord 1991;6:180-182.

4. Steckley JL, Ebers GC, Cader MZ, McLachlan RS. An autosomal dominant disorder with episodic ataxia, vertigo, and tinnitus. Neurology 2001;57:1499-1502.

5. Farmer TW, Mustian VM. Vestibulocerebellar ataxia: a newly defined hereditary syndrome with periodic manifestations. Arch Neurol 1963;8:471-480.

6. Escayg A, De Waard M, Lee DD, et al. Coding and noncoding variation of the human calcium-channel $\beta 4$-subunit gene $C A C N B 4$ in patients with idiopathic generalized epilepsy and episodic ataxia. Am J Hum Genet 2000;66:1531-1539.

7. Jen JC, Wan J, Palos TP, Howard BD, Baloh RW. Mutation in the glutamate transporter EAAT1 causes episodic ataxia, hemiplegia, and seizures. Neurology 2005;65:529-534.

8. Auburger G, Ratzlaff T, Lunkes A, et al. A gene for autosomal dominant paroxysmal choreoathetosis/spasticity (CSE) maps to the vicinity of a potassium channel gene cluster on chromosome $1 \mathrm{p}$, probably within $2 \mathrm{cM}$ between D1S443 and D1S197. Genomics 1996;31:90-94.

9. Griggs RC, Nutt JG. Episodic ataxias as channelopathies. Ann Neurol 1995;37:285-287.

10. Ophoff RA, Terwindt GM, Vergouwe MN, et al. Familial hemi- plegic migraine and episodic ataxia type- 2 are caused by mutations in the Ca2 + channel gene CACNL1A4. Cell 1996;87:543-552.

11. Brandt T, Strupp M. Episodic ataxia type 1 and 2 (familial periodic ataxia/vertigo). Audiol Neurootol 1997;2:373-383.

12. Imbrici P, Eunson LH, Graves TD, et al. Late-onset episodic ataxia type 2 due to an in-frame insertion in CACNA1A. Neurology 2005;65:944-946.

13. Gancher ST, Nutt JG. Autosomal dominant episodic ataxia: a heterogeneous syndrome. Mov Disord 1986;1:239-253.

14. Jen J, Kim GW, Baloh RW. Clinical spectrum of episodic ataxia type 2. Neurology 2004;62:17-22.

15. Brandt T, Strupp M. Migraine and vertigo: Classification, clinical features and special treatment considerations. Headache Currents 2006;3:12-19.

16. Oh AK, Lee H, Jen JC, Corona S, Jacobson KM, Baloh RW. Familial benign recurrent vertigo. Am J Med Genet 2001;100: 287-291.

17. Lempert T, Neuhauser H. Migrainous vertigo. Neurol Clin 2005; 23:715-30, vi.

18. Sasaki O, Jen JC, Baloh RW, Kim GW, Isawa M, Usami S. Neurotological findings in a family with episodic ataxia. J Neurol 2003;250:373-375

19. Rucker JC, Jen J, Stahl JS, Natesan N, Baloh RW, Leigh RJ. Internuclear ophthalmoparesis in episodic ataxia type 2. Ann N Y Acad Sci 2005;1039:571-574.

20. Mochizuki Y, Kawata A, Mizutani T, et al. Hereditary paroxysmal ataxia with mental retardation: a clinicopathological study in relation to episodic ataxia type 2. Acta Neuropathol (Berl) 2004;108: 345-349.

21. Spacey SD, Materek LA, Szczygielski BI, Bird TD. Two novel CACNA1A gene mutations associated with episodic ataxia type 2 and interictal dystonia. Arch Neurol 2005;62:314-316.

22. Van Bogaert P, Szliwowski HB. EEG findings in acetazolamideresponsive hereditary paroxysmal ataxia. Neurophysiol Clin 1996; 26:335-340.

23. Imbrici P, Jaffe SL, Eunson LH, et al. Dysfunction of the brain calcium channel Cav2.1 in absence epilepsy and episodic ataxia. Brain 2004;127:2682-2692.

24. Vighetto A, Froment JC, Trillet M, Aimard G. Magnetic resonance imaging in familial paroxysmal ataxia. Arch Neurol 1988;45: 547-549.

25. Hawkes CH. Familial paroxysmal ataxia: report of a family. J Neurol Neurosurg Psychiatry 1992;55:212-213.

26. Bain PG, O'Brien MD, Keevil SF, Porter DA. Familial periodic cerebellar ataxia: a problem of cerebellar intracellular $\mathrm{pH}$ homeostasis. Ann Neurol 1992;31:147-154.

27. Harno H, Heikkinen S, Kaunisto MA, et al. Decreased cerebellar total creatine in episodic ataxia type 2: a 1H MRS study. Neurology 2005;64:542-544.

28. Vahedi K, Joutel A, Van Bogaert P, et al. A gene for hereditary paroxysmal cerebellar ataxia maps to chromosome 19p. Ann Neurol 1995;37:289-293.

29. von Brederlow B, Hahn AF, Koopman WJ, Ebers GC, Bulman DE. Mapping the gene for acetazolamide responsive hereditary paryoxysmal cerebellar ataxia to chromosome 19p. Hum Mol Genet 1995; 4:279-284.

30. Shapiro MS, Gomeza J, Hamilton SE, et al. Identification of subtypes of muscarinic receptors that regulate $\mathrm{Ca}^{2+}$ and $\mathrm{K}^{+}$channel activity in sympathetic neurons. Life Sci 2001;68:2481-2487.

31. Eunson LH, Graves TD, Hanna MG. New calcium channel mutations predict aberrant RNA splicing in episodic ataxia. Neurology 2005;65:308-310.

32. Wan J, Khanna R, Sandusky M, Papazian DM, Jen JC, Baloh RW. CACNA1A mutations causing episodic and progressive ataxia alter channel trafficking and kinetics. Neurology 2005;64:2090-2097.

33. Guida S, Trettel F, Pagnutti S, et al. Complete loss of P/Q calcium channel activity caused by a CACNA1A missense mutation carried by patients with episodic ataxia type 2. Am J Hum Genet 2001; 68:759-764.

34. Wappl E, Koschak A, Poteser M, et al. Functional consequences of $\mathrm{P} / \mathrm{Q}-$ type $\mathrm{Ca}^{2+}$ channel Cav2.1 missense mutations associated with episodic ataxia type 2 and progressive ataxia. J Biol Chem 2002; 277:6960-6966. 
35. Jodice C, Mantuano E, Veneziano L, et al. Episodic ataxia type 2 (EA2) and spinocerebellar ataxia type 6 (SCA6) due to CAG repeat expansion in the CACNA1A gene on chromosome 19p. Hum Mol Genet 1997;6:1973-1978.

36. Tottene A, Fellin T, Pagnutti S, et al. Familial hemiplegic migraine mutations increase $\mathrm{Ca}^{2+}$ influx through single human CaV2.1 channels and decrease maximal CaV2.1 current density in neurons. Proc Natl Acad Sci USA 2002;99:13284-13289.

37. Zhuchenko O, Bailey J, Bonnen P, et al. Autosomal dominant cerebellar ataxia (SCA6) associated with small polyglutamine expansions in the $\alpha 1 \mathrm{~A}$-voltage-dependent calcium channel. Nat Genet 1997;15:62-69.

38. Maselli RA, Wan J, Dunne V, et al. Presynaptic failure of neuromuscular transmission and synaptic remodeling in EA2. Neurology 2003;61:1743-1748.

39. Walter JT, Alvina K, Womack MD, Chevez C, Khodakhah K. Decreases in the precision of Purkinje cell pacemaking cause cerebellar dysfunction and ataxia. Nat Neurosci 2006;9:389-397.

40. Strupp M, Kalla R, Dichgans M, Freilinger T, Glasauer S, Brandt T. Treatment of episodic ataxia type 2 with the potassium channel blocker 4-aminopyridine. Neurology 2004;62:1623-1625.

41. Hirose H, Arayama T, Takita J, Igarashi T, Hayashi Y, Nagao Y. A family of episodic ataxia type 2: no evidence of genetic linkage to the CACNA1A gene. Int J Mol Med 2003;11:187-189.

42. Cader MZ, Steckley JL, Dyment DA, McLachlan RS, Ebers GC. A genome-wide screen and linkage mapping for a large pedigree with episodic ataxia. Neurology 2005;65:156-158.

43. D'Adamo MC, Imbrici P, Sponcichetti F, Pessia M. Mutations in the KCNAl gene associated with episodic ataxia type- 1 syndrome impair heteromeric voltage-gated $\mathrm{K}^{+}$channel function. FASEB J 1999;13:1335-1345.

44. Sappey-Marinier D, Vighetto A, Peyron R, Broussolle E, Bonmartin A. Phosphorus and proton magnetic resonance spectroscopy in episodic ataxia type 2. Ann Neurol 1999;46:256-259.

45. Fletcher CF, Lutz CM, O'Sullivan TN, et al. Absence epilepsy in tottering mutant mice is associated with calcium channel defects. Cell 1996;87:607-617.

46. Fureman BE, Hess EJ. Noradrenergic blockade prevents attacks in a model of episodic dysfunction caused by a channelopathy. Neurobiol Dis 2005;20:227-232.

47. Weisz CJ, Raike RS, Soria-Jasso LE, Hess EJ. Potassium channel blockers inhibit the triggers of attacks in the calcium channel mouse mutant tottering. J Neurosci 2005;25:4141-4145.

48. Lorenzon NM, Lutz CM, Frankel WN, Beam KG. Altered calcium channel currents in Purkinje cells of the neurological mutant mouse leaner. J Neurosci 1998;18:4482-4489.

49. Mori Y, Wakamori M, Oda S, et al. Reduced voltage sensitivity of activation of P/Q-type $\mathrm{Ca}^{2+}$ channels is associated with the ataxic mouse mutation rolling Nagoya $\left(\operatorname{tg}^{\mathrm{rol}}\right)$. J Neurosci 2000;20:56545662.

50. Calandriello L, Veneziano L, Francia A, et al. Acetazolamide- responsive episodic ataxia in an Italian family refines gene mapping on chromosome 19p13. Brain 1997;120:805-812.

51. Griggs RC, Moxley RT 3rd, Lafrance RA, McQuillen J. Hereditary paroxysmal ataxia: response to acetazolamide. Neurology 1978; 28:1259-1264.

52. Harno H, Hirvonen T, Kaunisto MA, et al. Acetazolamide improves neurotological abnormalities in a family with episodic ataxia type 2 (EA-2). J Neurol 2004;251:232-234.

53. Griggs RC, Engel WK, Resnick JS. Acetazolamide treatment of hypokalemic periodic paralysis: prevention of attacks and improvement of persistent weakness. Ann Intern Med 1970;73:39-48.

54. Vroom FW, Jarrell MA, Maren TH. Acetazolamide treatment of hypokalemic periodic paralysis: probable mechanism of action. Arch Neurol 1975;32:385-392.

55. Johnsen T. Effect upon serum insulin, glucose and potassium concentrations of acetazolamide during attacks of familial periodic hypokalemic paralysis. Acta Neurol Scand 1977;56:533-541.

56. Goulon M, Raphael JC, Simon N. Periodic familial paralysis with hypokalemia: hemodynamic and metabolic studies: favorable effect of acetazolamide [In French]. Rev Neurol (Paris) 1978;134: 655-672.

57. Donat JR, Auger R. Familial periodic ataxia. Arch Neurol 1979; 36:568-569.

58. Zasorin NL, Baloh RW, Myers LB. Acetazolamide-responsive episodic ataxia syndrome. Neurology 1983;33:1212-1214.

59. Kuzmenkin A, Muncan V, Jurkat-Rott K, et al. Enhanced inactivation and $\mathrm{pH}$ sensitivity of $\mathrm{Na}^{+}$channel mutations causing hypokalaemic periodic paralysis type II. Brain 2002;125:835-843.

60. Woodhull AM. Ionic blockage of sodium channels in nerve. J Gen Physiol 1973;61:687-708.

61. Spacey SD, Hildebrand ME, Materek LA, Bird TD, Snutch TP. Functional implications of a novel EA2 mutation in the P/Q-type calcium channel. Ann Neurol 2004;56:213-220.

62. Brunt ER, van Weerden TW. Familial paroxysmal kinesigenic ataxia and continuous myokymia. Brain 1990;113:1361-1382.

63. Scoggan KA, Friedman JH, Bulman DE. CACNA1A mutation in a EA-2 patient responsive to acetazolamide and valproic acid. Can J Neurol Sci 2006;33:68-72.

64. Strupp M, Schuler O, Krafczyk S, et al. Treatment of downbeat nystagmus with 3,4-diaminopyridine: a placebo-controlled study. Neurology 2003;61:165-170.

65. Etzion Y, Grossman Y. Highly 4-aminopyridine sensitive delayed rectifier current modulates the excitability of guinea pig cerebellar Purkinje cells. Exp Brain Res 2001;139:419-425.

66. Kullmann DM, Hanna MG. Neurological disorders caused by inherited ion-channel mutations. Lancet Neurol 2002;1:157-166.

67. Kordasiewicz HB, Gomez CM. Molecular pathogenesis of spinocerbellar ataxia type 6. Neurotherapeutics 2007;4:285-294.

68. Rajakulendran S, Schorge S, Kullmann DM, Hanna MG. Episodic ataxia type 1: A neuronal potassium channelopathy. Neurotherapeutics 2007;4:258-266. 